\title{
Pentobarbital Anaesthesia in the Herring and Lesser Black-backed Gull
}

\author{
JUAN D. DELIUS
}

Department of Zoology, Oxford

\begin{abstract}
A procedure for long lasting general anaesthesia in gulls (Larus sp.) is described. It is based on an initial basal intramuscular dose of pentobarbital sodium, supplemented if necessary by intravenous injection to effect of the same agent. Additional intramuscular pentobarbital is used to extend the duration of anaesthesia. The labile respiration of the birds is supported with oxygen. In cases of respiratory failure, intravenous methetharimide is an effective reactivator. A survival rate of better than 95 per cent has been achieved with this method in gulls undergoing neurosurgery for $2-3 \mathrm{hr}$.
\end{abstract}

\section{INTRODUCTION}

IN THE course of a research programme requiring prolonged neurosurgery in the Herring Gull (Larus argentatus) and the Lesser Black-backed Gull (Larus fuscus) a method for anaesthetizing these birds had to be developed. The operation consists of the stereotactic placement of several electrodes into deep structures of the brain for electrical stimulation and lasts 2 or $3 \mathrm{hr}$ (Delius, 1966). As the birds are hand reared it was important to keep losses to a minimum. Since relatively little can be found in the literature on long-lasting anaesthesia for birds, it is perhaps worthwhile to describe a procedure which is now followed successfully. For reviews on avian anaesthesia see Jordan et al. (1960), Westhues and Fritsch (1961), Lumb (1963), Graham-Jones (1964).

\section{METHODS}

Pentobarbital sodium, $60 \mathrm{mg} / \mathrm{ml} \dagger$ is given intramuscularly at a dosage of $1 \cdot 3-1 \cdot 4$ $\mathrm{ml}$ per $\mathrm{kg}$, divided approximately equally into the pectoral muscle at both sides of the crest of the sternum about $\frac{1}{4}$ in. lateral to it (Donovan, 1958). The average weight of the caged gulls used was $960(750-1250) \mathrm{g}$, they are in good healthy

\footnotetext{
*The work has been supported by grants from the U.S. Air Force Office of Scientific Research through the European Office of Aerospace Research and by a grant of the Scientific Research Council to Prof. N. Tinbergen, F.R.S.

†Nembutal-Abbot.
} 
condition and starved for $24 \mathrm{hr}$. For optimum results it has been found that the exact dosage has to be adjusted from case to case, depending on the experience with the preceding operation; apparently there are slight seasonal variations in the susceptibility to pentobarbitone which have not yet been worked out with sufficient detail. It is clear though, that moulting is correlated with a depression of the pentobarbitone threshold. For other sources of variation see Arnall (1964). The dosages indicated are, however, safe limits.

\section{ANAESTHESIA}

Usually surgical anaesthesia, recognizable by a limp neck, is induced within 10-20 min after injection. In some occasions the birds will experience convulsive fits before reaching surgical depth. This can be stopped or minimized by placing the bird in darkness. In any case, the birds should not be disturbed once injected since experience shows that this has marked negative effects. Where disturbance cannot be avoided it is suggested that a tranquilizer should be given as premedication. Wilgus (1960) recommends reserpin for this purpose. In other contexts we have found that chloroprothixene $* 15 \mathrm{mg} / \mathrm{ml}$ is a powerful and long-term tranquilizer for birds, given intramuscularly at a dose of $0.50-0.75 \mathrm{ml} / \mathrm{kg}$.

A few birds (three in twenty-five) did not reach surgical depth after $30 \mathrm{~min}$ with the initial intramuscular dose. These were then, but not before, injected to effect with pentobarbitone into the vena basilica. For this it is important that the pentobarbitone is diluted to half strength with distilled water just before use for intravenous injection. The drowsy birds are placed on the back, one wing is extended and firmly held so, the feather on the ventral surface of the arm around the humeroulnar joint are wetted so that the vein can be found more easily. It is not advisable to pluck any feathers-except some very small ones-close to the vein since haemorrhage will then obscure the site of canulation. This can be easily achieved with a 22 gauge hypodermic needle if the vein is approached posteriorly. $\dagger$ If haemorrhage occurs before the vein has been successfully canulated it is best to turn to the other wing. Injection must proceed very slowly, no more than $0.5 \mathrm{ml}$ of the diluted pentobarbitone per min. The effect can be assessed by the increasing winking of the eyelids and should be stopped as soon as the eyes remain closed. In addition it is convenient to place the head of the bird over the edge of the table so that the relaxation of the neck can be observed as well. The dosage required is usually around $0.5 \mathrm{ml}$ of the dilute pentobarbitone per $\mathrm{kg}$. To attempt to supplement, in this situation, the initial intramuscular dose by a further intramuscular dose is definitely contraindicated. Intravenous injection without previous intramuscular dosage is feasible if the pentobarbitone is diluted as indicated above and injection proceeds very slowly (Sykes, 1964), but at least with gulls we have found that is is difficult to keep the birds still for a sufficiently long period, and therefore the risk of vein rupture is great (Gandal, 1956). This risk is adequately minimized by intramuscular predosage. Also, exclusive intravenous administration will maintain surgical anaesthesia for no longer than about 15-20 min and additional doses are

*'Taractan-Geigy.

$\dagger$ More recently, because of easy access, we have successfully attempted canulation of footweb veins. 
difficult to give. Autopsies carried out 2 or 3 weeks after intramuscular administration of pentobarbitone failed to give evidence of any changes in the muscles involved (compare Sanger and Smith, 1957). Intraperitoneal injection of pentobarbitone has been found to give very variable results and is therefore clearly contraindicated (but see Keymer, 1958).

To supplement the often rather shallow and labile respiration the birds are given an oxygen-air mixture as soon as they reach surgical depth. This mixture is produced by flowing 1-2 $1 /$ min medical oxygen regulated by an ordinary flow-meter through an air mixing valve. The mixture which contains approximately 40 per cent oxygen is administered into the mouth simply by placing a $\frac{1}{4}$ in. tubing between the mandibles.

Respiration has to be watched carefully. Should it become irregular then the trachea is intubated with a $\frac{3}{8}$ in. diameter rubber tube cut bevelled at $30^{\circ}$ after opening the beak widely. The tube, which fits loosely into the trachea permitting the escape of surplus air during artificial respiration, is introduced about 1 in. into the trachea and fixed to the upper mandible with some elastic plaster (Hill and Noakes, 1964). It is advisable to place the bird in such a way that the neck slopes. gently downwards to avoid accumulation of mucus in the trachea. Occasionally the endotracheal tube has to be taken out and cleaned. As an adequate respirator was. not available during this study, in emergencies the "kiss-of-life" method was used enriching the operators air with peribuccal administration of the air-oxygen mixture previously mentioned. This is continued untill the bird's own respiration resumes.

Since this might often take up to $30 \mathrm{~min}$ or more, such cases were usually injected with methetharimide $* 70 \mathrm{mg} / \mathrm{ml}$ intravenously at an approximate dose of $0.75 \mathrm{ml} / \mathrm{kg}$ slowly at a rate of $1 \mathrm{ml} / \mathrm{min}$ This was found to always reactivate respiration in about $5 \mathrm{~min}$. In most cases of our restricted experience with this drug, anaesthesia will then temporarily be too shallow for surgery but within 5 min or so the bird relapses to sufficient depth to permit continuation.

The initial dose of pentobarbitone will keep the bird at an adequate anaesthetic level for $45 \mathrm{~min}$, or longer. At the first signs of recovery $1 / 3$ of the original dose is injected intramuscularly into the same site. This has been found to keep birds anaesthetized for a further $30 \mathrm{~min}$ or more, this procedure is repeated up to a total of three or four times, to give the $2-3 \mathrm{hr}$ required to complete the neurosurgery procedures. These supplementary doses did not lead to complications.

\section{RECOVERY}

No particular measures were taken during recovery except keeping the birds in a warm place and continuing oxygen administration until they open their eyes and begin to stir. Apart from some drowsiness during the next day the birds showed no ill effects.

In our experience cardiac arrest only occured after prolonged respiratory arrest. If oxygen had been administered the heart will only stop 5 or $10 \mathrm{~min}$ after respiratory stoppage and is probably due to hypoxia; there is therefore sufficient time to begin artificial respiration. Heartbeat can be either monitored by auscultation or more

*Megmide-Astra Hewlett. 
simply by palpation of the carotids on the ventral side of the base of the neck. In gulls one can also assess, at least coarsely, blood oxygenation by examining the coloration of the veins in the translucent footwebs.

The body temperature regulation of the anaesthetized birds seems to be poor and it appears necessary to supplement it (Arnall, 1964), with i.r. radiation of an ordinary $100 \mathrm{~W}$ bulb which is also used for illumination of the surgical field.

Routinely the surgical field is instilled subcutaneously with $1 \mathrm{ml} 2 \%$ lignocaine with epinephrine* 1:80,000 to avoid pain in case of temporary shallowness of anaesthesia, which may occur occasionally, and to restrict bleeding. This did not appear to interfere with the general anaesthesia.

\section{RESULTS}

In a series of twenty-five birds in which the described procedure has been followed, there was one fatality. In four birds artificial respiration had to be given temporarly and in two of these birds Megmide was administered as well. This compares with a mortality of ten birds out of twenty of a preceding series in which oxygen administration and other details of the procedure were lacking.

\section{CONCLUSIONS}

It is possible that the method could be improved if pentobarbitone was replaced by a combined anaesthetic consisting of pentobarbital sodium, chloral hydrate and magnesium sulphate, $\uparrow$ which according to American workers (Gandal, 1956; Nottebohm, personal communication) has a greater safety margin than pentobarbitone. A further possibility is the use of gaseous agents which appear to give reliable results (Hill and Noakes, 1964; Marley and Payne, 1964; Hodos, personal communication).

Acknowledgements -I wish to thank Mrs. J. Macfarland and Miss G. Thompson for assistance during operations and Dr. N. BLURTON-Jones for certain suggestions.

\section{REFERENCES}

Arnale, L. (1964) Aspects of anaesthesia in cage birds. In (Ed. Graham-Jones, O.) Small Animal Anaesthesia, p. 137. Pergamon Press, Oxford.

Delius, J. D. (1966) Some techniques for electrical brain stimulation of small unrestrained animals. Med. biol. Engng. 4, 393.

Donovan, C. A. (1958) Restraint and anaesthsia of cage birds. Vet. Med. 53, 541.

Gandal, C. P. (1956) Satisfactory general anaesthesia in birds. 7. Am. vet. med. Ass. 128, 332.

Graham-Jones, O. (Ed.) (1964) Small Animal Anaesthesia. Pergamon Press, Oxford.

Hill, K. J. and Noakes, D. E. (1964) Cyclopropane anaesthesia in the fowl. In (Ed. GrairamJones, O.) Small Animal Anaesthesia, p. 123. Pergamon Press, Oxford.

Jordan, F. T. W., SAndford, J. and Wright, A. (1960) Anaesthesia in the fowl. F. comp. Path. 90, 437.

Keymer, T. F. (1958) The diagnosis and treatment of common psittacine diseases. Mod. Vet. Pract. 39, 22.

Lums, W. V. (1963) Small Animal Anaesthesia. Lea and Febiger, Philadelphia.

*Xilotox 2\% E80-Pharmaceutical Manufacturing Co.

†Equithesin-Jensen Salsbery, U.S.A. 
Marley, E. and Payne, J. P. (1964) Halothane anesthesia in the fowl. In (Ed. Graham-Jones, O.) Small Animal Anaesthesia, p. 127. Pergamon Press, Oxford.

SANGer, V. L. and Sмiтh, H. R. (1957) General anaesthesia in birds. J. Am. vet. med. Ass. 131, 52.

Syres, A. H. (1964) Some aspects of anaesthesia in the adult fowl. In (Ed. Graham-Jones, O.) Small Animal Anaesthesia, p. 117. Pergamon Press, Oxford.

Westhues, M. and Fritsch, R. (1961) Die Narkose der Tiere. Parey, Berlin.

Wilgus, H. S. (1960) Reserpine for tranquilizing geese. 2nd Conf. Use of Reserpine in Poultry Production. University Press, Minnesota.

Résumé-L'auteur décrit un procédé pour obtenir une anesthésie prolongée chez les goelandes (Larus sp). Il s'agit d'une injection intramusculaire de pentobarbitone de soude, suivie, si nécessaire, d'une injection intraveineuse du même produit. Des injections intramusculaires supplémentaires sont données si l'on veut prolonger l'anesthésie. La respiration labile de ces oiseaux est supporte par l'administration d'oxygène; en cas d'apnie l'auteur recommande l'usage intraveineux de méthetharimide. comme un excellent réanimateur. Plus de $95 \%$ des cas soumis a cette méthode survécurent à des opérations neuro-chirurgicales qui durèrent deux a trois heures.

Zusammenfassung-Eine Methode zur Dauernarkose der Seemöven (Larus sp.) wird angegeben. Man gibt zum Beginn eine intramuskuläre Dose von Pentobarbitalsodium und, falls nötig, nachfolgend eine intravenöse Injektion desselben Mittels. Falls man die Narkose weiter verlängern will gibt man nochmals Pentobarbitalsodium intramuskulär. Die labile Atmung dieser Vögel wird mit Sauerstoff unterstuit. Falls die Atmung versagt, findet man die intravenöse Injektion von Methetharimid höchst wirksam. Mit dieser Methode bleiben mehr als 95\% der Möven am Leben nach zwei-bis dreistündigen Operationen am Zentralnervensystem. 